\title{
A Buck Converter Based On PID Controller for Voltage Step-Down Application
}

\author{
Ankita Pandey ${ }^{1}$, Dr. Dharmendra Singh ${ }^{2}$ \\ ${ }^{1}$ M.Tech (Power System), Dr. C.V. Raman University Bilaspur, Chhattisgarh, India \\ ${ }^{2}$ H.O.D. Electrical and Electronics department, Dr. C.V. Raman University, Bilaspur, Chhattisgarh, India
}

\begin{abstract}
This paper present a pulse width modulation non-isolated buck converter using PID controller. The buck converter constituted by one Gto, one inductor, one capacitor, one diode and one load resistor. In this the buck converter connected to the PID controller, PID controller calculate an error value as the difference between a measured process variable and a desired set point. The proportional $P$ depends on the present error, integral I accumulate the past error and derivative $D$ predict the future error. The performance of buck converter has been studied and is undertaken for their theoretical verification, graphical performance and matlab simulation.
\end{abstract}

Keywords: dc-de converter, buck converter, pulse width modulation, PID controller

\section{Introduction}

Pulse width modulation (PWM) dc-de converter are widely employed in numerous application e.g. audio amplifier, power supplies, fuel cell powered system and fork lift vehicles, although many other ones can be easily found. Convention hard switching converter with a single active switch such as buck, boost, buck-boost, cuk and zeta typically present low power density, while to attempts the further minimize the size of filter elements of lead to increased switching losses, compromising the efficiency of converters.

In order to overcome the limitation, several soft switching approaches have been introduced. Soft switching is supposed to reduce the overlap between voltage and current during the commutation and can be classified in either active or passive method.

DC-DC converter converts the DC voltage signal from high level to low level or it can be vise versa depending on the type of converter used in system. Buck converter is one of the most important component of circuit it converts the high level of DC signal into low voltage. In buck converter, a high speed switching device are placed and the better efficiency of power conversion with the steady state can be achieved.

A proportional-integral-derivative(PID) is a control loop feedback mechanism widely used in industrial control system. A PID controller calculates an error value as the difference between measured process variable and desired set point. The controller attempts to minimize the error by adjusting the process through use of a manipulated variable.

The PID controller algorithm involves three separate constant parameters, and is accordingly sometimes called three-term control: the proportional, the integral and derivative values, denoted P, I, and D. Simply put, these values can be interpreted in terms of time: $P$ depends on the present error, I on the accumulation of past errors, and $\mathrm{D}$ is a prediction of future errors, based on current rate of change. ${ }^{[1]}$ The weighted sum of these three actions is used to adjust the process via a control element such as the position of a control valve, a damper, or the power supplied to a heating element. For a discrete time case, the term PSD, for proportional-summation-derivative, is often used. ${ }^{[2]}$

A PID controller relies only on the measured process variable, not on knowledge of the underlying process, making it a broadly useful controller. ${ }^{[3]}$ By tuning the three parameters in the PID controller algorithm, the controller can provide control action designed for specific process requirements. The response of the controller can be described in terms of the responsiveness of the controller to an error, the degree to which the controller overshoots the setpoint, and the degree of system oscillation. Note that the use of the PID algorithm for control does not guarantee optimal control of the system or system stability.

Some applications may require using only one or two terms to provide the appropriate system control. This is achieved by setting the other parameters to zero. A PID controller will be called a PI, PD, P or I controller in the absence of the respective control actions. PI controllers are fairly common, since derivative action is sensitive to measurement noise, whereas the absence of an integral term may prevent the system from reaching its target value due to the control action.

\section{The Buck Converter}

The fig. 2.1 shows the dc-dc buck converter. In the buck converter the ac source connected to the diode rectifier and it use as a controlled switch to elicit unidirectional power flow from input to output. The one inductor and one capacitor are use to store and transfer the energy from input to output. The voltage and current waveform are smooth by filter. The circuit is assumed to be operating in continuous condition mode (CCM). The capacitor is large enough to offer a constant output voltage.

In the description of converter operation, all the component like inductor, capacitor etc. are assumed to be ideal and the converter operates in CCM. In the CCM, in inductor the current flows continuously over one switching period. In the buck converter the operation according to switching function, the switch is either on or off and this results in two

\section{Volume 4 Issue 12, December 2015}




\section{International Journal of Science and Research (IJSR) \\ ISSN (Online): 2319-7064}

Index Copernicus Value (2013): 6.14 | Impact Factor (2014): 5.611

circuit state. When the switch is turn on this is first subcircuit state, the diode is reverse biased and the inductor current flow through the switch. When the switch is turn off this is the second sub-circuit state, current freewheels the diode, which is shown in Fig.2.3

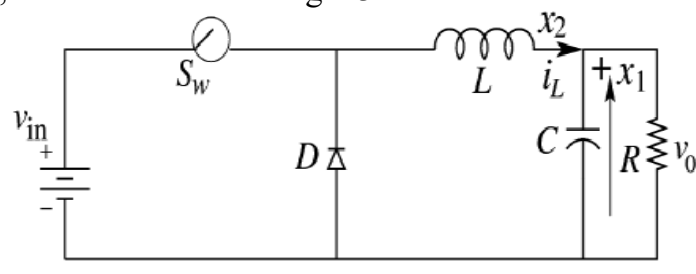

Figure 2.1: Buck Converter

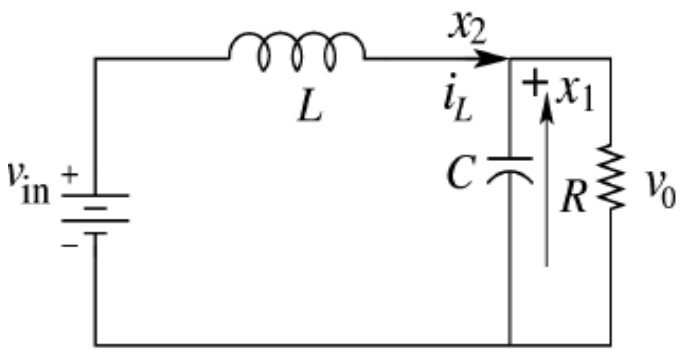

Figure 2.2: Turn on switch

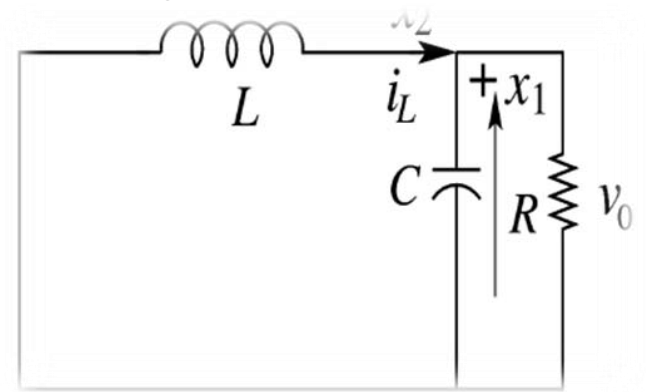

Figure 2.3: Turn off switch

\section{Proportional- Derivative- Integral (PID)}

All the three control strategies are combined to get PID controller and it use to control the over steady state and transient error. In this the control error is a linear combination of error. The PID is a combination of all control components capable of producing adequate stability. The PID controller provides both an acceptable degree of error reduction and an acceptable stability and damping. Fig. 3.1 shows

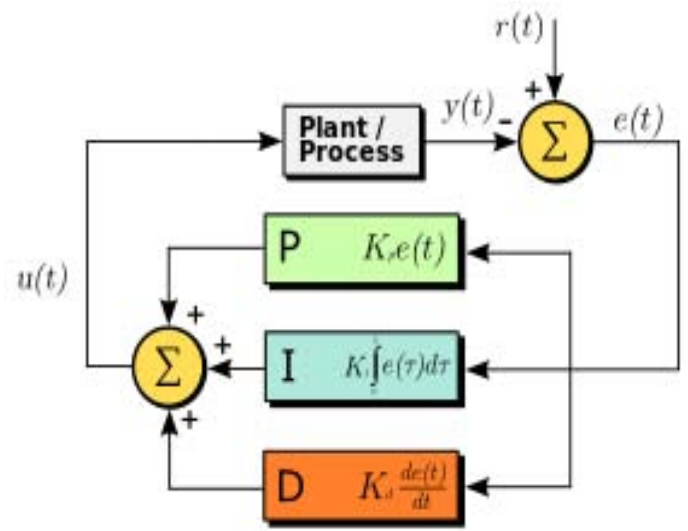

Figure 3.1: The block diagram of PID controller.

\section{Control Method}

Fig. 4.1 shows the block diagram with PID methods that can be used to control DC-DC converters and the disturbances that can be influence on the behaviour of the converter and its stability. The feedback signal may be the output voltage, the inductor current, or both. The feedback control either analog or digital. The PID is linear control method.

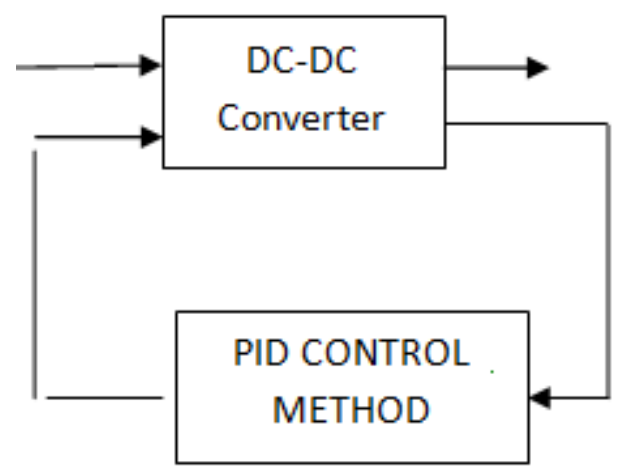

Figure 4.1:

\section{PID Controller}

PID controllers are dominant and popular and have been widely used since 1940's because one can obtain the desired system response and it can control the system. The basic AC modelling approach is a common averaging technique used for PID modelling. After the circuit is modelled, we go through the design of PID controller with the help of Matlab in a simple way to get an overall system with good quality performance. Simulink model of the converter is built up and the controller obtained is added to the model.

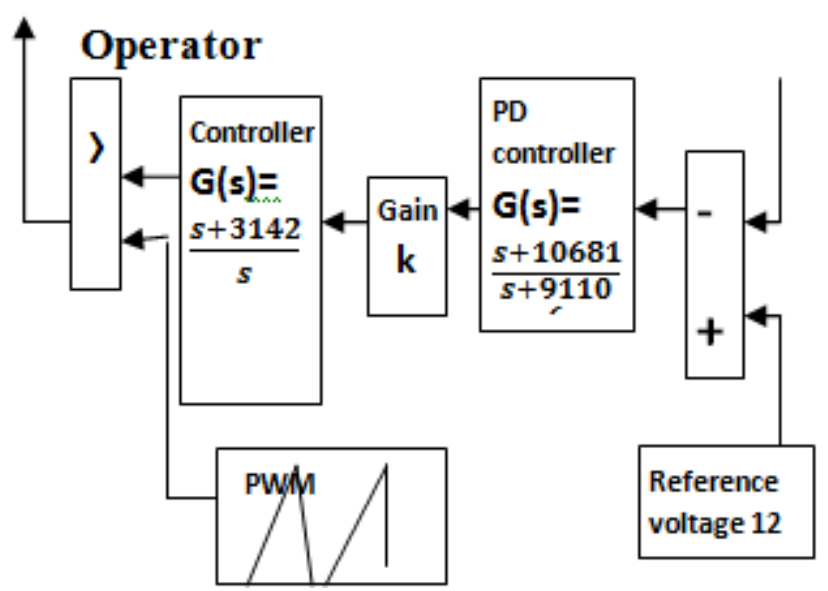

Figure 5.1: A block diagram of controller includes PID controller 


\section{International Journal of Science and Research (IJSR) \\ ISSN (Online): 2319-7064}

Index Copernicus Value (2013): 6.14 | Impact Factor (2014): 5.611

MATLAB Simulation model of buck with PID controller:

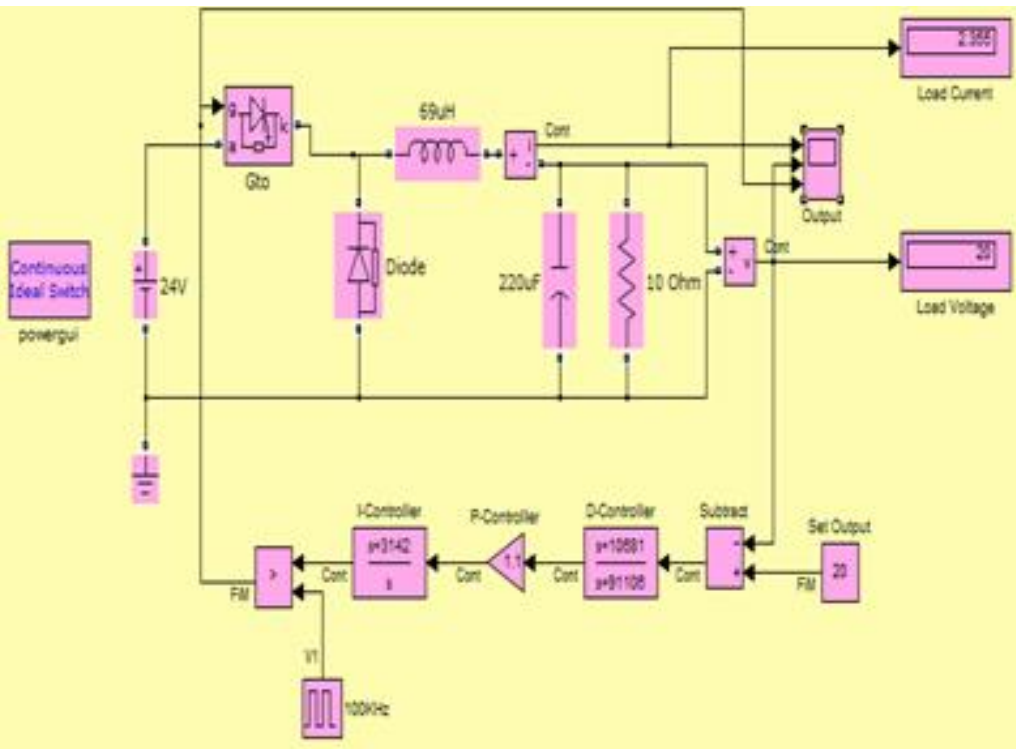

Figure 6.1: Simulation Diagram for buck converter with PID controller

The above fig. Shows the simulation diagram of buck converter with PID controller. In this model we get advantage of both buck converter and PID controller.

Table 1: Main circuit Parameter

\begin{tabular}{|c|c|c|}
\hline Parameter name & symbol & value \\
\hline Input voltage & Vin & 24 \\
\hline Output voltage & Vou & 20 \\
\hline indutor & L & $69 \mu \mathrm{h}$ \\
\hline capacitor & C & $220 \mu \mathrm{f}$ \\
\hline resistance & R & $10 \Omega$ \\
\hline freqency & F & $100 \mathrm{khz}$ \\
\hline
\end{tabular}

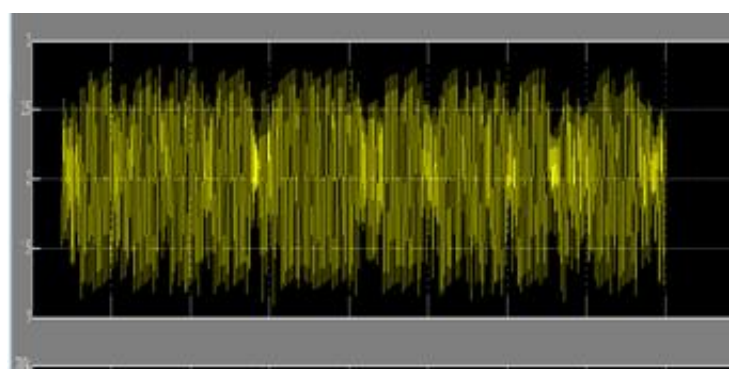

Figure 6.2: load current

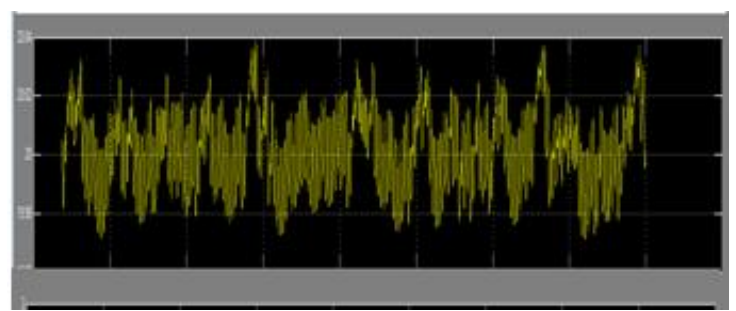

Figure 6.3: load voltage

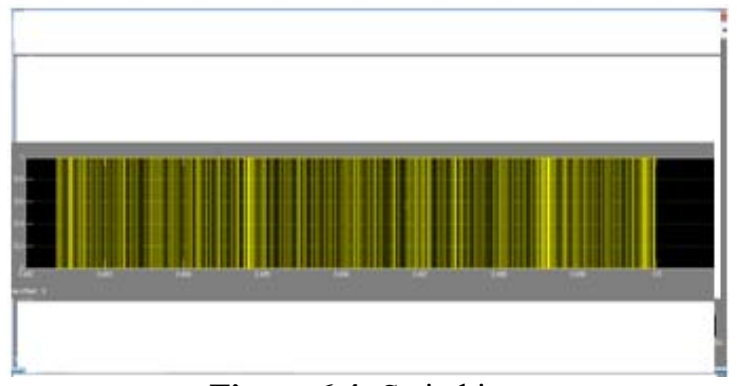

Figure 6.4: Switching

The above fig 6.2, 6.3, 6.4 shows the output of the simulation model.

\section{Conclusion}

Non -isolated DC-DC buck converter with PID controller are presented in this paper. In this paper the performance of buck converter and PID controller are studied and implemented in matlab simulink. By the help of PID controller we achieve the better performance of buck converter. The above topology can be promising solution for high step-down application. In this the load current and load voltage were obtain.

\section{References}

[1] Shelgaonkar (Bindu) Arti Kamalakar, N. R. Kulkarni, "PERFORMANCE VERIFICATION OF DC-DC BUCK CONVERTER USING SLIDING MODE CONTROLLER FORCOMPARISON WITH THE EXISTING CONTROLLERS - ATHEORETICAL APPRO International Journal of Advances in Engineering \& Technology, Jan 2012.

[2] M.Ahmed, M.Kuisma, P. Silventoinen, "Implementing Simple Procedure for Controlling Switch Mode Power Supply Using Sliding Mode Control as a Control Technique", XIII-th International Symposium on Electrical Apparatus and technologies (Siela). May 2003, pp 9-14, Vol. 1

\section{Volume 4 Issue 12, December 2015}




\section{International Journal of Science and Research (IJSR) \\ ISSN (Online): 2319-7064}

Index Copernicus Value (2013): 6.14 | Impact Factor (2014): 5.611

[3] Hongmei Li and Xiao Ye "Sliding-Mode PID Control of DC-DC Converter", 5th IEEE Conference on Industrial Electronics and Applications.

[4] V.I.Utkin, Sliding modes and their application in variable structure systems, MIR Publishers, Moscow,1978

[5] G. Spiazzi, P. Mattavelli, L. Rossetto, L. Malesani, "Application of Sliding Mode Control to Switch-Mode Power Supplies," Journal of Circuits, Systems and Computers (JCSC), Vol. 5, No. 3, September 1995,pp.337-354.

\section{Author Profile}

Ankita Pandey is pursuing M.Tech (Power System) from Dr. C.V. Raman University Bilaspur. She has completed B.E. (Electrical Engineering) From C.S.V.T.U. Bhilai (C.G.), India

Dr. Dharmendra Singh: H.O.D. Electrical and Electronics department, Dr. C.V. Raman University, Bilaspur. Recently he has done his Phd from Dr. C. V. Raman University Bilaspur (C.G.), India 